\title{
Spatial-temporal dynamics of desert vegetation and its responses to climatic variations over the last three decades: a case study of Hexi region in Northwest China
}

\author{
YANG Xuemei $^{1,2}$, LIU Shizeng $^{1 *}$, YANG Taibao ${ }^{2}$, XU Xianying $^{1}$, KANG Caizhou ${ }^{1}$, TANG \\ Jinnian $^{1}$, WEI Huaidong ${ }^{1}$, Mihretab G GHEBREZGABHER ${ }^{2,3}$, LI Zhiqi ${ }^{4}$ \\ ${ }^{1}$ State Key Laboratory Breeding Base of Desertification and Aeolian Sand Disaster Combating, Gansu Desert Control Research \\ Institute, Lanzhou 730070, China; \\ ${ }^{2}$ Institute of Glaciology and Ecogeography, College of Earth and Environmental Sciences, Lanzhou University, Lanzhou \\ 730000, China; \\ ${ }^{3}$ Eritrea Institute of Technology, College of Education, Mai-Nefhi 12676, Eritrea; \\ ${ }^{4}$ Wuwei Natural Protection Station, the Management Bureau of Gansu Qilianshan National Nature Reserve, Wuwei \\ 733000, China
}

\begin{abstract}
Analysis of spatial-temporal variations of desert vegetation under the background of climate changes can provide references for ecological restoration in arid and semi-arid areas. In this study, we used the Global Inventory Modeling and Mapping Studies (GIMMS) NDVI data from 1982 to 2006 and Moderate Resolution Imaging Spectroradiometer (MODIS) NDVI data from 2000 to 2013 to reveal the dynamics of desert vegetation in Hexi region of Northwest China over the past three decades. We also used the annual temperature and precipitation data acquired from the Chinese meteorological stations to analyze the response of desert vegetation to climatic variations. The average value of NDVImax (the maximum NDVI during the growing season) for desert vegetation in Hexi region increased at the rate of $0.65 \times 10^{-3} / a(P<0.05)$ from 1982 to 2013 , and the significant increases of NDVImax mainly appeared in the typical desert vegetation areas. Vegetation was significantly improved in the lower reaches of Shule and Shiyang river basins, and the weighted mean center of desert vegetation mainly shifted toward the lower reaches of the two basins. Almost 95.32\% of the total desert vegetation area showed positive correlation between NDVImax and annual precipitation, indicating that precipitation is the key factor for desert vegetation growth in the entire study area. Moreover, the areas with non-significant positive correlation between NDVImax and annual precipitation mainly located in the lower reaches of Shiyang and Shule river basins, this may be due to human activities. Only $7.64 \%$ of the desert vegetation showed significant positive correlation between NDVImax and annual precipitation in the Shule River Basin (an extremely arid area), indicating that precipitation is not the most important factor for vegetation growth in this basin, and further studies are needed to investigate the mechanism for this phenomenon.
\end{abstract}

Keywords: desert vegetation; NDVI; global warming; spatial-temporal variations; Hexi region

Citation: YANG Xuemei, LIU Shizeng, YANG Taibao, XU Xianying, KANG Caizhou, TANG Jinnian, WEI Huaidong, Mihretab G GHEBREZGABHER, LI Zhiqi. 2016. Spatial-temporal dynamics of desert vegetation and its responses to climatic variations over the last three decades: a case study of Hexi region in Northwest China. Journal of Arid Land, 8(4): 556-568. doi: 10.1007/s40333-016-0046-3

\footnotetext{
*Corresponding author: LIU Shizeng (E-mail: shzliu@126.com; yxm9693@163.com)

Received 2015-08-04; revised 2016-01-18; accepted 2016-03-23

(C) Xinjiang Institute of Ecology and Geography, Chinese Academy of Sciences, Science Press and Springer-Verlag Berlin Heidelberg 2016
} 
Vegetation, the most important component in terrestrial ecosystems and the most sensitive to climatic variations, can reflect the changes in the atmosphere, water and soil in natural environments (Gerten et al., 2004; Piao et al., 2006; Guo et al., 2014; Lei et al., 2014; Yang et al., 2014; Mao et al., 2015). Remote sensing technique is widely used to analyze the spatial-temporal dynamics of vegetation at different spatial scales because it has the advantages of long-time and large spatial scales as well as convenience. The Normalized Difference Vegetation Index (NDVI) is directly correlated with greenness and indirectly correlated with photosynthetic activity in vegetation, which can be acquired from GIMMS (Global Inventory Modeling and Mapping Studies, includes NDVIg (NDVI first generation) and NDVI3g (NDVI third generation), MODIS (Moderate Resolution Imaging Spectroradiometer Studies) and SPOT satellite remote sensing datasets. The NDVI is widely adopted to study the regional vegetation changes (Murray et al., 2013).

Desert vegetation in arid and semi-arid areas is a key component of ecosystems and is sensitive to climate changes (Jamali et al., 2014). China is one of the countries heavily affected by desertification. Vegetation in the margins of arid deserts in mid-latitude Asia significantly increased from 1982 to 1998 but decreased thereafter (Jeong et al., 2011). The arid and semi-arid regions of Northwest China are located in central Eurasia, which have low precipitation and sparse vegetation, and are also heavily affected by desertification. Some previous studies have revealed that the variations of vegetation in most areas of Northwest China display a significant correlation with precipitation and temperature, while some other studies have stated that vegetation growth has a low correlation either with precipitation or temperature ( $\mathrm{Li}$ and Shi, 2000; Li et al., 2005; Li et al., 2009; Dai et al., 2010; Zhao et al., 2011; Liu and Ren, 2012; Li and Chen, 2014; Wang et al., 2015; Zhang and Wang, 2015). The inconsistencies of these results require further study. Therefore, it is necessary to analyze the spatial-temporal dynamics of vegetation and its responses to climatic variations over long-time scales in Northwest China, especially for desert vegetation area. The Hexi region in Northwest China represents a typical gravel desert ecosystem, consisting of peripheral desert, desert-oasis ecotone and central oasis. However, at present, few studies have focused on the changes of desert vegetation and its responses to climatic variations in this region at long-time and large spatial scales (Deng, 2006; Guo et al., 2008; Wang et al., 2010; Wei et al., 2014).

Based on all the above, with the combination of GIMMS NDVI (1982-2006) and MODIS NDVI (2001-2013) remote sensing data (Xin et al., 2007; Zhang et al., 2011; Zhou et al., 2014), this study aimed to reveal the spatial-temporal variations of desert vegetation and its responses to temperature and precipitation under the background of climatic warming over the past 30 years in Hexi region of China. The results will be of great theoretical and practical significance to evaluate the conditions of land ecosystems, to regulate the ecosystem sustainably for the local government, and to offer important insights into the ecological restorations in temperate desert areas.

\section{Materials and methods}

\subsection{Study area}

The Hexi region $\left(37^{\circ} 17^{\prime}-42^{\circ} 48^{\prime} \mathrm{N}, 93^{\circ} 23^{\prime}-104^{\circ} 12^{\prime} \mathrm{E}\right.$; $800-2,500 \mathrm{~m}$ asl; Fig. 1) is mainly located in the western and northern parts of Kumtag, Badain Jaran and Tengger deserts, Northwest China. The region is mainly composed of alluvial and fluvial plains, shallow mountains, oases, deserts and Gobi. Its eastern, central and western parts comprise the Shiyang, Heihe and Shule river basins, respectively, which are characterized by low precipitation and high evaporation (Meng et al., 2013). The Hexi region mainly includes two types of desert vegetation: (1) typical temperate desert vegetation (including small trees, shrubs and undershrubs), which is distributed at elevations of 1,320-1,800 m; and (2) mountain desert vegetation (a transition vegetation between typical desert vegetation and alpine vegetation), which is distributed at elevations of 1,800-2,300 $\mathrm{m}$ (Fig. 2). Alpine deserts are scattered in the mountain areas, at more than 4,300 m elevation (Liu, 2001; Wang et al., 2001). This study aimed to focus on the typical desert vegetation and mountain desert vegetation regions. 


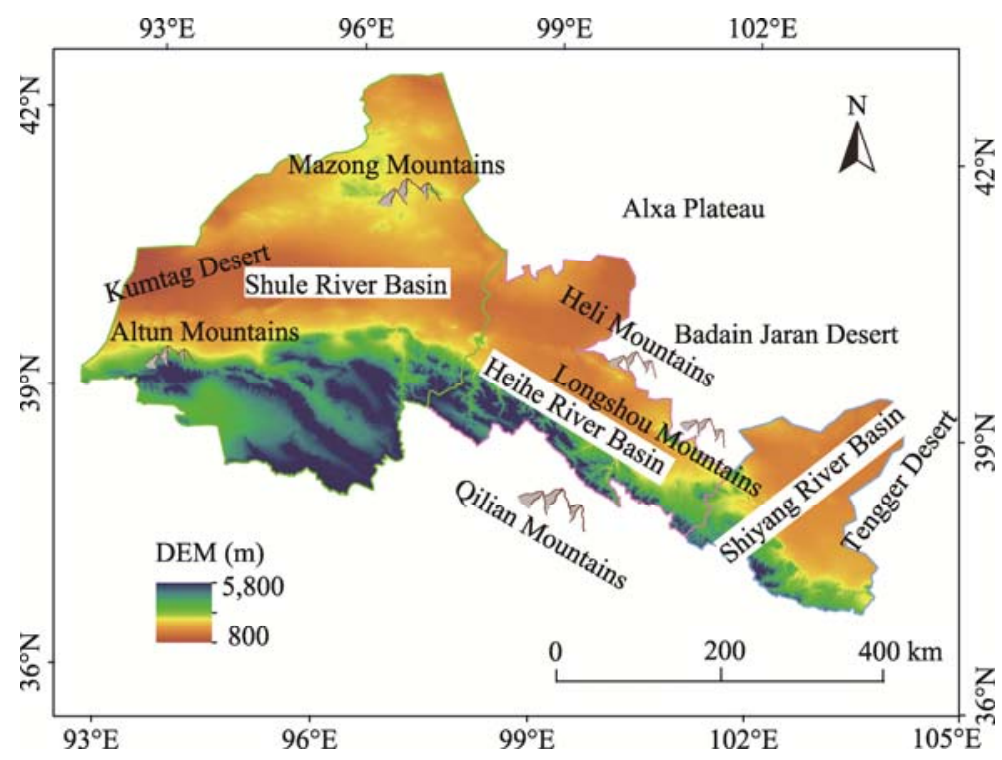

Fig. 1 Map of Hexi region. DEM, digital elevation model.

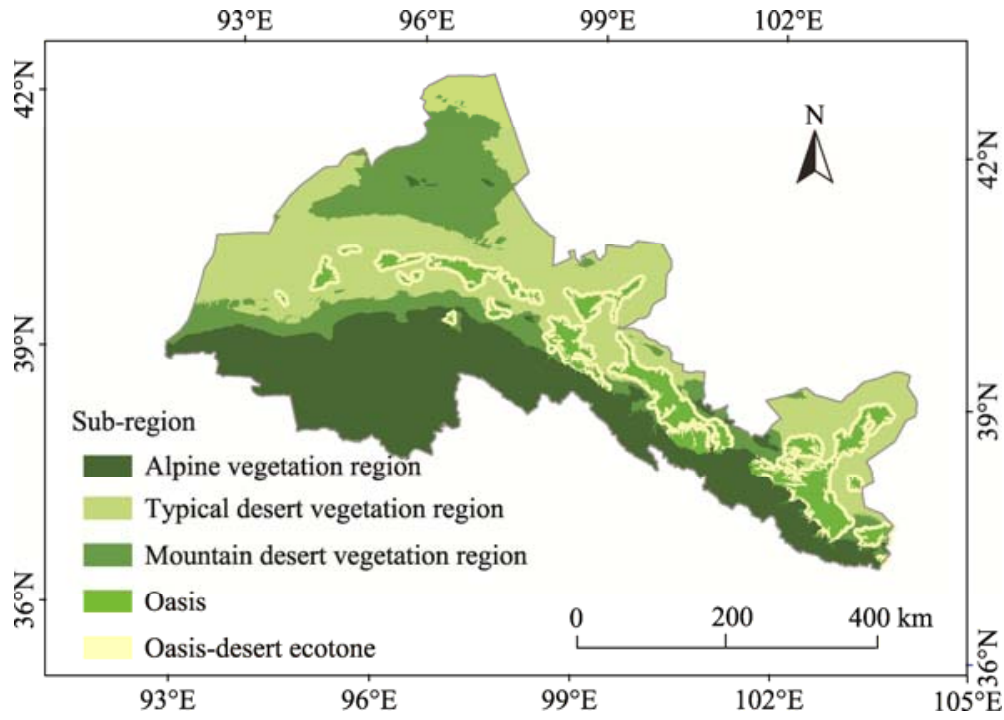

Fig. 2 Distribution of eco-geographical regions of Hexi region

\subsection{Data sources and preprocessing}

\subsubsection{GIMMS NDVI and MODIS NDVI data}

A 15-day GIMMS NDVI dataset with 8-km spatial resolution from 1982-2006 produced by GLCF (Global Land Cover Facility) at the University of Maryland, USA was used in this study. The GIMMS NDVI dataset has been corrected for the variations causing by calibration, view geometry and volcanic aerosols, and other factors which were not related to the actual vegetation changes. It is widely used in studies of long-time dynamics of vegetation at regional and global scales (Jamali et al., 2014). The 16-day MODIS NDVI time series data (MODIS13Q1) spanning 2000-2013 with 250-m spatial resolution were downloaded from the EOS NASA Land Processes Distributed Active Archive Center (https://lpdaac.usgs.gov). The data were acquired from the MODIS tiles (h24v04, h24v05, h25v04, h25v05, h26v04 and h26v05). The dataset was possibly affected by aerosols, ice, snow, illumination angle and sensor angle of view, which can cause outliers in the time series. NDVImax represents the best growth status for vegetation in a year. Therefore, it was used to study the spatial variations of desert vegetation over the past 30 years, 
and area with NDVImax $<0.1$ was omitted. In this study, the Savtzky-Golay (S-G) method was used for noise reduction, and the monthly maximum GIMMS NDVI and MODIS NDVI data (NDVImax) were obtained using the Maximum Value Composite (MVC) method. Both the MODIS NDVI and GIMMS NDVI were projected to WGS84/Albers Conical Equal Area projection, and the GIMMS NDVI was resampled to $250 \mathrm{~m}$ to have the same spatial resolution with MODIS NDVI (Zhou et al., 2014).

\subsubsection{Integration of GIMMS NDVI and MODIS NDVI data}

Since the time series of GIMMS NDVImax and MODIS NDVImax were obtained from different remote sensors and exhibited certain spectra, it was necessary to check the consistency of the two datasets. In this study, the NDVImax data were overlapped for seven years (2000-2006) and divided into the ascending (a total of 35 months from April to August) and descending periods (a total of 49 months from September to March) for analyzing the correlation of GIMMS NDVImax and MODIS NDVImax. We found that the correlation coefficients of mean NDVImax between the two datasets in the ascending and descending periods were 0.8564 and 0.8389 , respectively, showing a significant correlation between the two datasets $(P<0.01)$. By the overlapping data of seven years, we established the linear regression equation between the time series data of GIMMS NDVImax and MODIS NDVImax during 2000-2006, and extended the time series of GIMMS NDVImax data to the year of 2013 (Fig. 3).

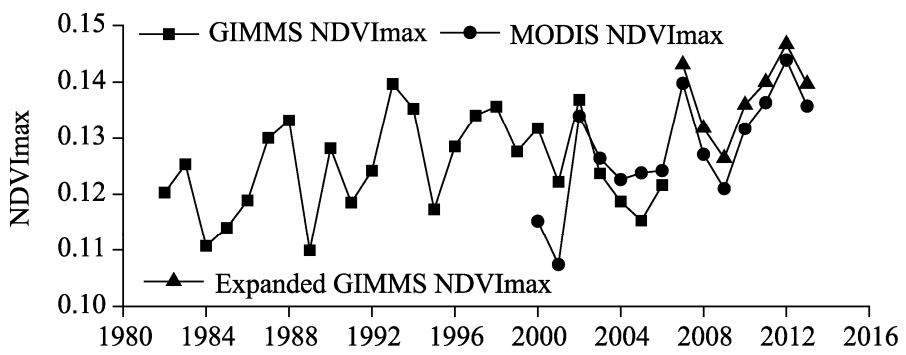

Fig. 3 Variations of NDVImax in Hexi region for 1982-2013

1.2.3 Meteorological and DEM (digital elevation model) data

The meteorological data were provided by the China Meteorological Data Sharing Service System (http://datamirror.csdb.cn/). Considering the revocation and removal of meteorological stations, we selected the monthly temperature and precipitation as well as annual temperature and precipitation data from 13 meteorological stations in low mountains, plains and $10 \mathrm{~km}$ buffer areas away from the study area during 1982-2013 to ensure the consistency of the meteorological data. The meteorological stations in this study included the Hongliu River, Mazong Mountains, Dunhuang, Dingxin, Gaotai, Alxa Right Banner, Zhangye, Shandan, Yongchang, Wuwei, Wushaoling and Jingtai stations. Furthermore, the months from May to October were regarded as the vegetation growing season (Zhao et al., 2001). The DEM data were provided by the International Scientific Data Service Platform (http://datamirror.csdb.cn/).

\subsection{Methods}

1.3.1 Change trends of NDVImax and climate variables

The linear time trend was estimated by regression as a function of time over the study period. To further investigate the change trends of NDVImax during the vegetation growing season, we examined the linear trends of NDVImax from 1982-2013 on a per-pixel basis (Mu et al., 2012).

$$
\text { Slope }_{\mathrm{NDVI}}=\frac{n \sum_{i=1}^{n} i \times \operatorname{NDVImax}_{i}-\sum_{i=1}^{n} i \times \sum_{i=1}^{n} \operatorname{NDVImax}_{i}}{n \sum_{i=1}^{n} i^{2}-\left(\sum_{i=1}^{n} i\right)^{2}} .
$$

Where, slope $\mathrm{NDVI}_{\mathrm{I}}$ is the slope of the change trends of NDVImax from 1982 to 2013 ; $n$ is the total 
monitoring year $(n=32) ; i$ is the sequence number of the monitoring year $(i=1982,1983, \ldots, 2013)$; NDVImax $_{i}$ is the maximum NDVI in the growing season of the $i^{\text {th }}$ year. The significance of changes in the trends was tested using an $F$ test. The results showed that the study area could be divided into five sub-regions according to the slope and significance values: significant decreasing area (slope $\mathrm{NDVI}_{\mathrm{ND}}<0, P \leq 0.01$ ), slightly significant decreasing area (slope $_{\mathrm{NDVI}}<0$, $0.01<P \leq 0.05)$, stable area $(P>0.05)$, slightly significant increasing area (slope $\mathrm{NDVI}_{\mathrm{N}}>0,0.01<P \leq 0.05$ ) and significant increasing area (slope $\mathrm{NDVI}_{\mathrm{I}}>0, P \leq 0.01$ ) (Mu et al., 2012).

1.3.2 Variations of weighted mean center (WMC) of desert vegetation

The center of gravity, also called the WMC, can be used to reveal the spatial lopsidedness and distribution regularity of objects. The distance changes from the gravity center shows the degree of deviation of the object, which can effectively reveal the spatial change trend and regularity of the object. In this study, the gravity center of desert vegetation in Hexi region was calculated using Eq. 2 (Song et al., 2005).

$$
\left(x_{\mathrm{wmc}}, y_{\mathrm{wmc}}\right)=\left[\frac{\sum_{i=1}^{n} w_{i} x_{i}}{\sum_{i=1}^{n} w_{i}}, \frac{\sum_{i=1}^{n} w_{i} y_{i}}{\sum_{i=1}^{n} w_{i}}\right] .
$$

Where, $x_{\mathrm{wmc}}$ and $y_{\mathrm{wmc}}$ refer to the longitude and latitude of the gravity center of desert vegetation, respectively; $x_{i}$ and $y_{i}$ refer to the longitude and latitude of the center at each pixel, respectively; and $w_{i}$ is the NDVImax of each pixel.

\subsubsection{Spatial interpolation of annual temperature and precipitation}

First, the correlation coefficients of annual precipitation with longitudes, latitudes and elevations of 13 meteorological stations from 1982 to 2013 (comprising 416 data) were calculated, as well as annual average temperature. The results indicated that all the correlation coefficients successfully passed the significance test (Table 1). We then simulated the annual average temperature (or annual precipitation) with longitude, latitude and elevation of each station in the multiple linear regression equations. Finally, we utilized the spline function interpolation to deal with the residual values (the difference between observed values and fitted values which were simulated from the regression equations for each meteorological station), and used the method of "multiple regression equation result+residual value" to develop the raster data of temperature and precipitation, of which the spatial resolution and projection were the same as those of the NDVI datasets.

Table 1 Pearson correlation coefficients of climatic variables with longitude, latitude and elevation

\begin{tabular}{cccc}
\hline Climatic variable & Longitude & Latitude & Elevation \\
\hline Annual average temperature & $-0.100^{*}$ & $0.127^{* *}$ & $-0.806^{* *}$ \\
Annual precipitation & $-0.713^{* *}$ & $0.589^{* *}$ & $0.709^{* *}$ \\
\hline
\end{tabular}

Note: ${ }^{*}$ and ${ }^{* *}$ mean significance at $P<0.05$ and $P<0.01$ levels, respectively.

1.3.4 Partial correlation analysis of NDVImax and climate variables

In this study, the partial correlations ( $r$ ) of NDVImax with annual average temperature and annual precipitation were calculated for each pixel on a year-to-year basis. The correlation was divided into six intervals by the $t$-test. The six intervals were as follows: significant negative correlation $(r<0, P \leq 0.01)$, slightly significant negative correlation $(r<0,0.01<P \leq 0.05)$, non-significant negative correlation $(r<0, P>0.05)$, non-significant positive correlation $(r>0, P>0.05)$, slightly significant positive correlation $(r>0,0.01<P \leq 0.05)$ and significant positive correlation $(r>0$, $P \leq 0.01$ ) (Zhang et al., 2011).

\section{Results}

\subsection{Annual average NDVImax of desert vegetation}

The area of mountain desert vegetation region occupied $17.94 \%$ of the total study area, and the 
typical desert vegetation region accounted for $34.57 \%$ of the total. Generally, the vegetation showed a decreasing tendency from southeast to northwest and increased with increasing altitude. Over the past 30 years, the annual average value of NDVImax for desert vegetation in the entire region was 0.1498 , while the values for mountain desert vegetation and typical desert vegetation were 0.1684 and 0.1272 , respectively (Fig. 4).

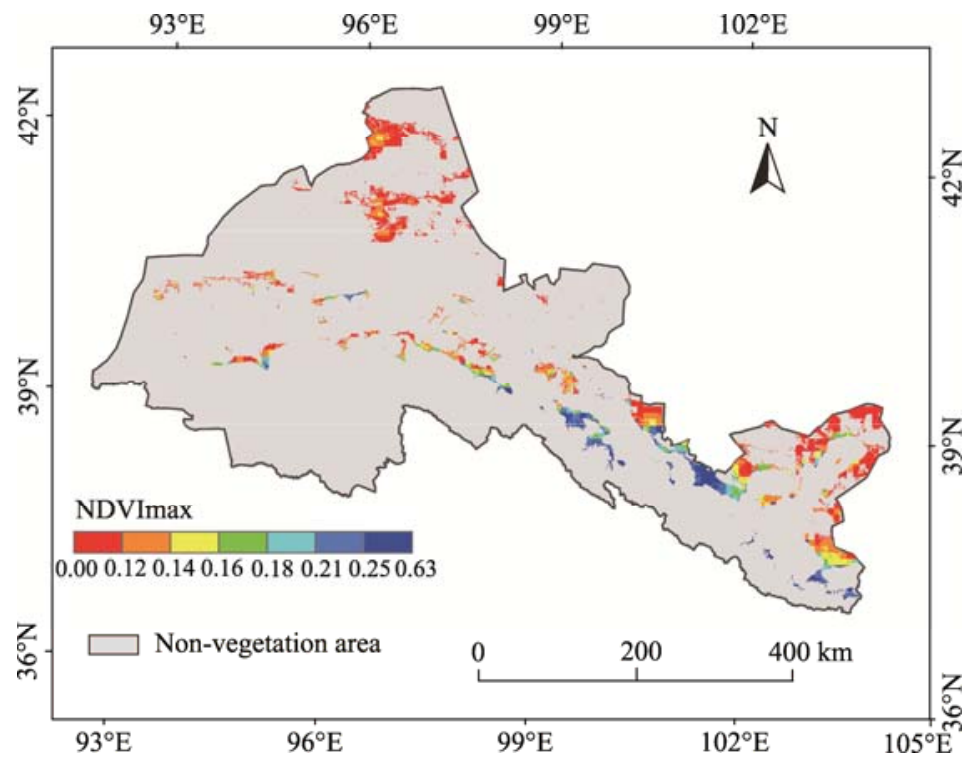

Fig. 4 Spatial distribution of average NDVImax for desert vegetation in Hexi region during 1982-2013

\subsection{Inter-annual variations of NDVImax for desert vegetation}

The average NDVImax of desert vegetation in Hexi region demonstrated an increasing trend with the rate of $0.65 \times 10^{-3} / \mathrm{a}$ during $1982-2013$, which can be roughly divided into two phases: fluctuating increasing at a rate of $0.35 \times 10^{-3} / \mathrm{a}$ from 1982 to $2000(P>0.05)$ and significant increasing at a rate of $4.21 \times 10^{-3}$ /a from 2001 to $2013(P<0.01$; Fig. 5). During the period 1982-2000, the increasing rate of NDVImax for typical desert vegetation was $1.10 \times 10^{-3} / \mathrm{a}(P<0.01)$, which was higher than that for mountain desert vegetation $\left(0.29 \times 10^{-3} / \mathrm{a} ; P>0.05\right)$. According to the statistics of variation in desert vegetation of different basins, the vegetation in the Shule River Basin showed a relatively significant increasing trend over the past 30 years, with the NDVImax increasing at a rate of $1.04 \times 10^{-3} / \mathrm{a}(P<0.01)$. Meanwhile, the increasing rates of NDVImax in the Shiyang and Heihe river basins were $0.54 \times 10^{-3} / \mathrm{a}(P>0.05)$ and $0.24 \times 10^{-3} / \mathrm{a}(P>0.05)$, respectively.

The average values of NDVImax for different ecological regions all showed significant increasing trends in 2001-2013. The increasing rate of NDVImax for typical desert vegetation was $4.24 \times 10^{-3} / \mathrm{a}(P<0.01)$, which was slightly higher than that for mountain desert vegetation $\left(4.19 \times 10^{-3} / \mathrm{a} ; P<0.05\right)$. The average NDVImax for desert vegetation in different inland basins also showed increasing trend in 2001-2013. Among which, the values for the Heihe and Shule river basins were higher, with the NDVImax increasing at the rates of $4.92 \times 10^{-3} / \mathrm{a}(P<0.01)$ and $4.83 \times 10^{-3} / \mathrm{a}(P<0.01)$, respectively, followed by the Shiyang River Basin, with the value of $3.02 \times 10^{-3} / \mathrm{a}(P<0.05)$. These results indicated that, at the regional scale, an increasing trend of NDVImax for desert vegetation occurred in the whole Hexi region over the past three decades, especially in the western Hexi region during the past 10 years.

\subsection{Spatial changes of NDVImax for desert vegetation}

2.3.1 Shifting of weighted mean center (WMC) for desert vegetation

The shifted direction of WMC for desert vegetation of the entire region included two trends (Fig. 6a). During 1982-2000, it mainly shifted in SE-NW (southeast-northwest) directions; after that, it mainly moved toward northwest direction. The shifted directions of WMC during 1982-2013 


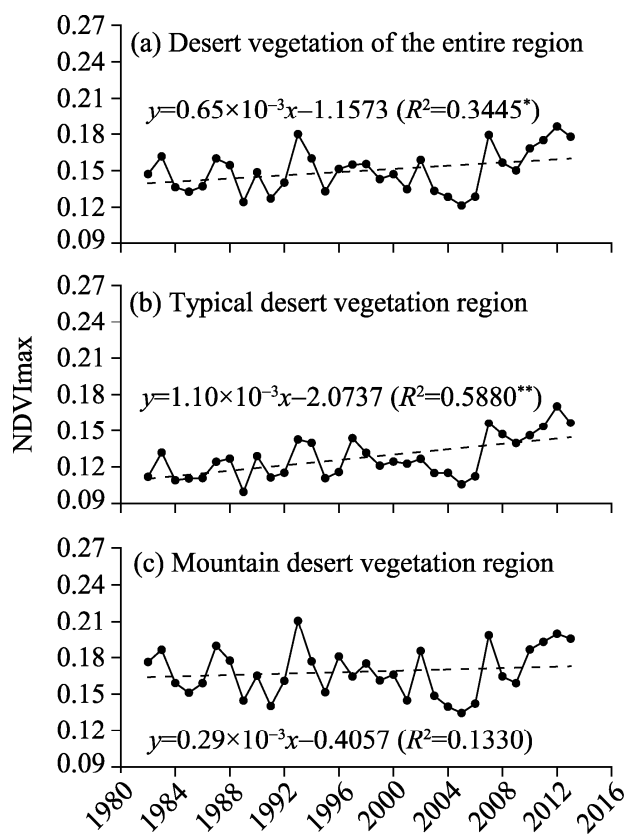

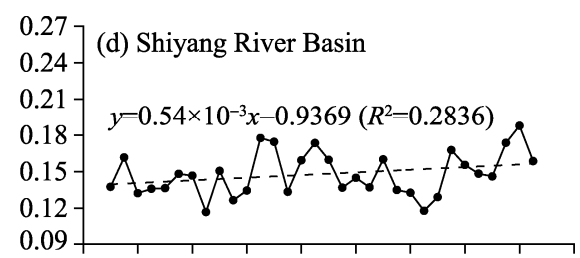
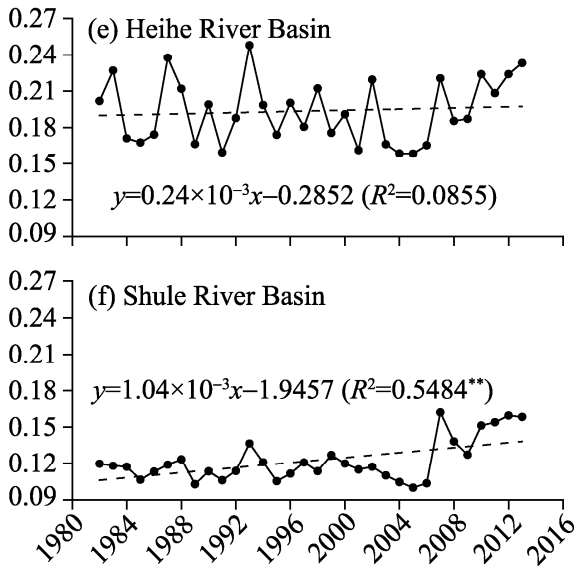

Fig. 5 Inter-annual changes of NDVImax in (a) desert vegetation of the entire region, (b, c) different types of desert vegetation region and $(\mathrm{d}, \mathrm{e}, \mathrm{f})$ desert vegetation of different river basins. ${ }^{*}$ and ${ }^{* *}$ mean significance at $P<0.05$ and $P<0.01$ levels, respectively.
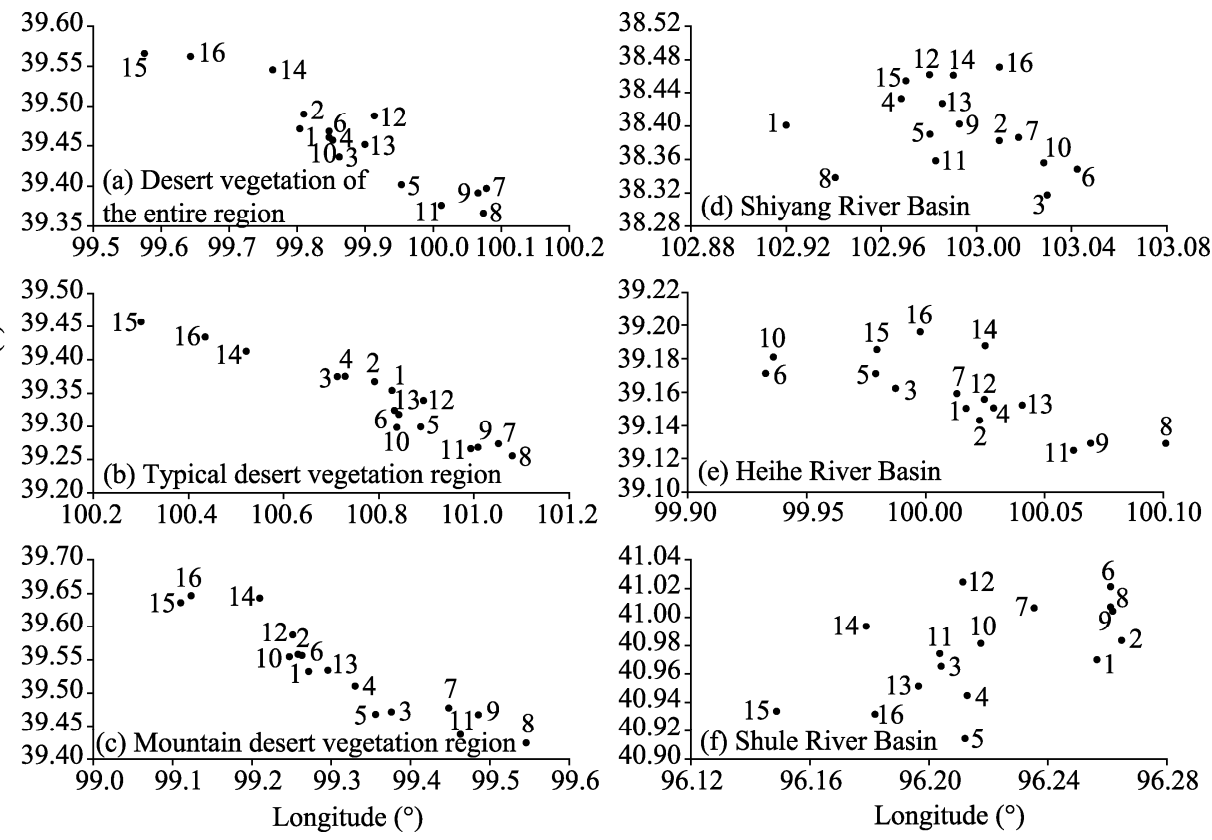

Fig. 6 Locations of the weighted mean center (WMC) for (a) desert vegetation of the entire region, (b, c) different types of desert vegetation region and $(\mathrm{d}, \mathrm{e}, \mathrm{f})$ desert vegetation of different river basins from 1982 to 2013. The Arabic numerals 1-16 indicate the years 1982, 1984, 1986, 1988, 1990, 1992, 1994, 1996, 1998, 2000, 2002, 2004, 2006, 2007, 2010 and 2013, respectively.

were similar between typical desert vegetation and mountain desert vegetation areas (Figs. 6b and c), showing that the improvement in desert vegetation conditions mainly happened in northwestern Hexi region in recent 10 years. Moreover, the variations of WMC of desert vegetation were completely different in the three river basins (Figs. 6d-f). The WMC of desert vegetation in the Shiyang River Basin mainly shifted in SE-NW (southeast-northwest) directions 
during 1982-2000, and then turned to the northeast direction. The WMC of desert vegetation in the Heihe River Basin were mainly developed in the SE-NW directions during 1982-2000, and then moved toward the east direction. The WMC of desert vegetation in the Shule River Basin mainly shifted to the NE-SW (northeast-southwest) directions during 1982-2000, and then changed to the northeast direction beginning in 2000. The results showed that the WMC of desert vegetation in the three river basins moved to the lower reaches generally, indicating that the growth conditions of desert vegetation in these basins were improved in recent 10 years.

\subsubsection{Spatial variation tendency of desert vegetation}

The variation rate of NDVImax for desert vegetation in Hexi region was calculated on a pixel-by-pixel basis (Fig. 7). The result showed that for the entire region, the significant increasing area and slightly significant increasing area accounted for $28.48 \%$ and $12.03 \%$ of the total desert vegetation area (hereafter called the area percentage), respectively. The sum of the two was larger than the sum of the significant decreasing and slightly significant decreasing areas (area percentages of $3.26 \%$ and $2.70 \%$, respectively). The area percentage of desert vegetation zones that remained stable was 53.53\%. Moreover, 35.94\% of desert vegetation in the Shule River Basin showed significantly increasing trend during 1982-2013, which was higher than those in the Shiyang River Basin (32.18\%) and Heihe River Basin (12.36\%). In addition, 40.70\% of typical desert vegetation significantly increased, while only $18.55 \%$ of mountain desert vegetation showed significantly increasing trend, demonstrating that the increasing desert vegetation mainly occurred in the typical desert vegetation areas.

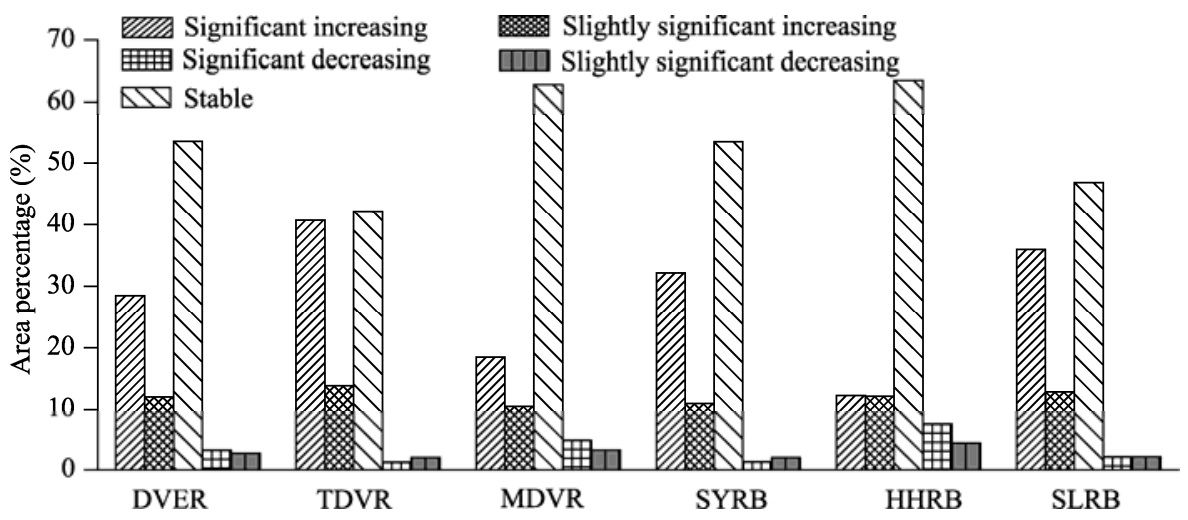

Fig. 7 Area percentages of desert vegetation changes in the entire region, typical and mountian desert vegetation regions, and different river basins. DVER: desert vegetation of the entire region; TDVR, typical desert vegetation region; MDVR, mountain desert vegetation region; SYRB, Shiyang River Basin; HHRB, Heihe River Basin; SLRB, Shule River Basin.

The significant increasing area of desert vegetation mainly occurred in the lower reaches of Shiyang and Shule river basins, the southern part of Mazong Mountains of Shule River Basin and the typical desert vegetation areas in the Heihe River Basin (Fig. 8). The regions that vegetation showing decreasing trend were small and discontinuously distributed in the transitional zones between the mountains desert vegetation and typical desert vegetation, and in the edge zones between the deserts and oases.

\subsection{Partial correlation analysis of NDVImax with temperature and precipitation}

In this study, the partial correlations of NDVImax with annual average temperature and annual precipitation were calculated for each pixel from 1982 to 2013 (Fig. 9). The results showed that the areas with significant negative correlation and slightly significant negative correlation between NDVImax and annual average temperature occupied $2.04 \%$ and $2.39 \%$ of the total desert vegetation area (hereafter called the area percentage), respectively (Fig. 9a). For the correlation between NDVImax and annual average temperature, the area percentages of significant positive correlation and slightly significant positive correlation were $23.57 \%$ and $12.61 \%$, respectively, 

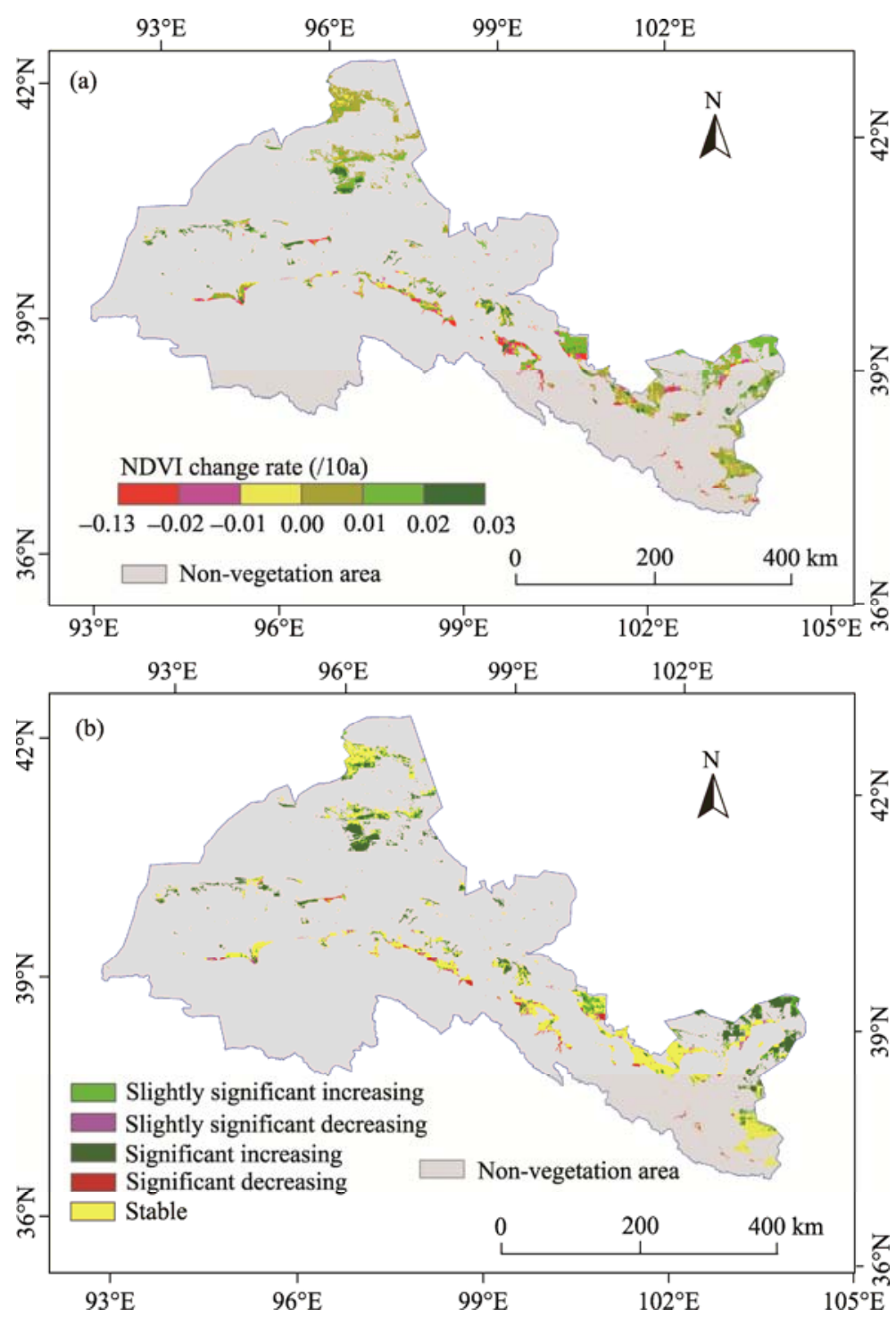

Fig. 8 The change rate of NDVImax (a) and spatial distribution of significance tests (b) for desert vegetation in Hexi region during 1982-2013

and those of non-significant positive correlation and non-significant negative correlation were $39.34 \%$ and $20.06 \%$, respectively. The areas where desert vegetation showed a higher correlation with temperature were mainly located in the mountain desert vegetation zones in the Shule River Basin and typical desert vegetation areas in the lower reaches of Shiyang River Basin, and were discontinuously distributed in the outer of the desert-oasis ecotone in the Heihe and Shule river basins. These results indicated that there was no significant correlation between NDVImax and annual average temperature in most areas of Hexi region.

The partial correlation statistics revealed that $25.70 \%$ and $23.57 \%$ of desert vegetation in Hexi region showed significant and slightly significant positive correlations between NDVImax and annual precipitation, respectively, which was mainly distributed in the mountain desert vegetation areas of Shiyang and Shule river basins (Fig. 9b). Areas where the correlation between NDVImax and annual precipitation showed slightly significant negative correlation and significant negative correlation accounted for $0.04 \%$ and $0.00 \%$ of the total desert vegetation area, respectively. Moreover, only $4.64 \%$ of the total desert vegetation area showed non-significant negative correlation between NDVImax and annual precipitation. These results demonstrated that 
precipitation is important for desert vegetation growth in the entire Hexi region. Moreover, significant correlation between NDVImax and annual precipitation was found in Hexi region during 1982-1999, with the correlation coefficient of $0.86(P<0.01)$. However, the value decreased to $0.34(P>0.05)$ after the year 2000 .

In Hexi region, $46.05 \%$ of the total desert vegetation area showed non-significant positive correlation between NDVImax and annual precipitation, which was mainly found in the lower reaches of Shiyang and Shule river basins. Moreover, $28.65 \%$ and $27.20 \%$ of the mountain desert vegetation region showed significant and slightly significant correlations between NDVImax and annual precipitation, respectively, which were higher than those of the typical desert vegetation region $(22.11 \%$ and $19.15 \%$, respectively).
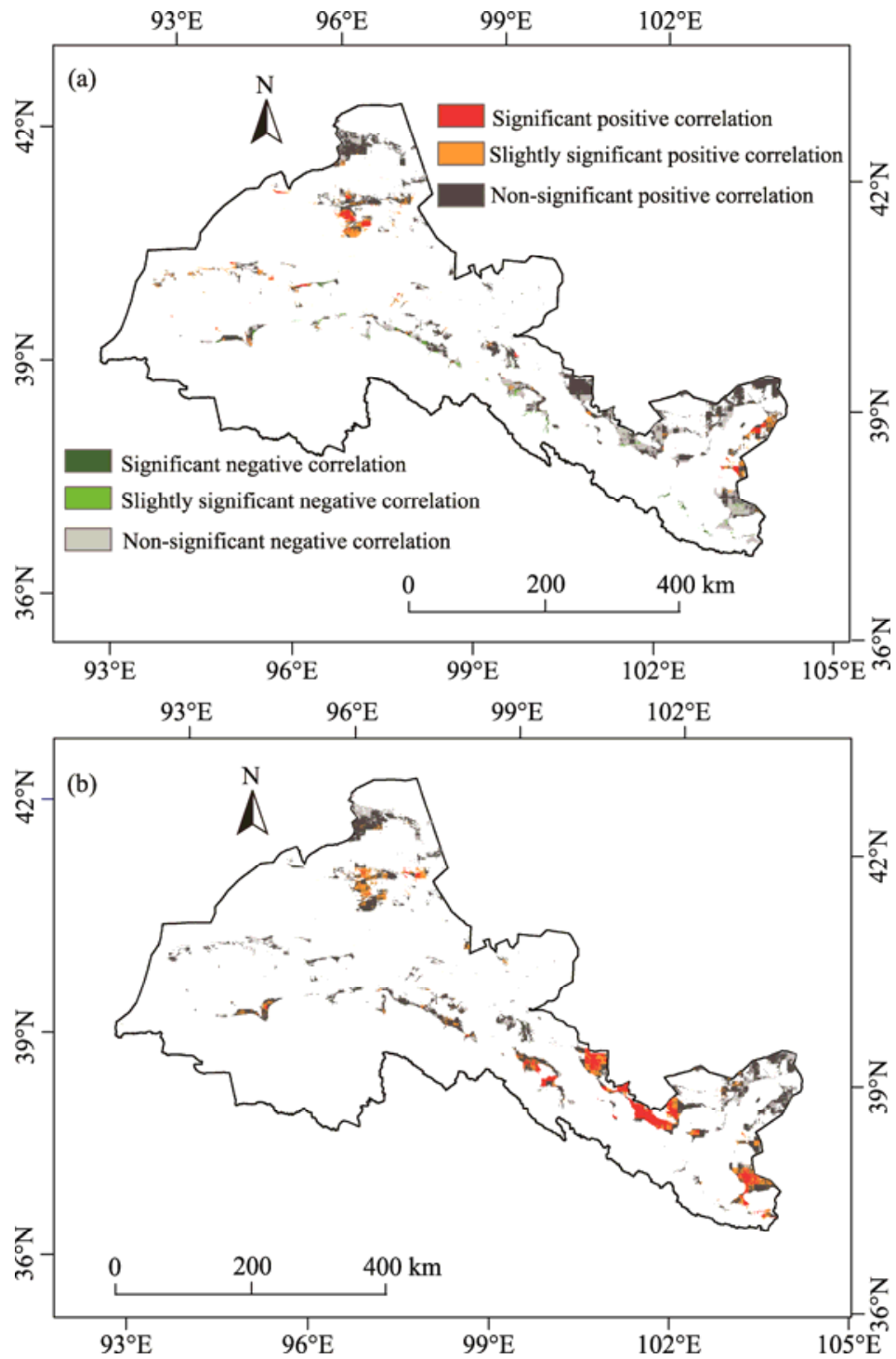

Fig. 9 Partial correlation of NDVImax of desert vegetation with (a) annual average temperature and (b) annual precipitation in Hexi region

\section{Discussion}

\subsection{Effect of human activities on desert vegetation}

Some previous studies have shown that the correlation of vegetation with temperature and 
precipitation was weak in arid lands of Northwest China (Dai et al., 2010; Li and Chen, 2014; Zhou et al., 2014; Zhang and Wang, 2015), especially over the last 10 years, which may be due to the combined effects of human activities and climate changes (Zhang et al., 2011; Han et al., 2015). The result was also found in this study. First, significant correlation between NDVImax of desert vegetation and annual precipitation existed in Hexi region during 1982-1999. However, the correlation decreased after the year 2000. Second, the area where NDVImax and annual precipitation showed no significant positive correlation at the inter-annual scale was mainly located in the lower reaches of Shiyang and Shule river basins. This may be influenced by human activities such as ecological design and measures for grazing prohibition, rotational grazing, grain for green, reasonable water allocation and increased ecological water consumption in the lower reaches of the river basins, especially in the Shiyang River Basin in the past 10 years. In addition, the water consumption plan may be one of the important reasons for the shifting direction of WMC of desert vegetation (toward the lower reaches) in different river basins. The uncertainty and quantification of human activities influence on vegetation changes are significant and complicated worldwide, and needed to be further studied.

\subsection{Correlation between NDVImax and annual precipitation in different ecological regions}

In general, there was a positive correlation between NDVImax and annual precipitation in Hexi region, and the area accounted for $95.32 \%$ of the total desert vegetation area. The result revealed that precipitation is the main factor for the growth of desert vegetation in the entire study area. This is consistent with many other studies in Northwest China (Li et al., 2005; Zhao et al., 2011; Liu and Ren, 2012; Wang et al., 2015). However, the correlation between NDVImax and annual precipitation differed in different ecological regions. First, the area where NDVImax and annual precipitation showed significant and slightly significant correlations in the mountain desert vegetation region was higher than that in the typical desert vegetation region. This difference may be caused by the lower drought tolerance and higher water requirement of mountain desert vegetation. Some previous studies have suggested that precipitation may be the key factor for desert vegetation growth in Northwest China, even for mountain forests and grasslands (Wang et al., 2015). However, not much researches have focused on the mountain desert vegetation (the transitional zone between typical desert vegetation and alpine vegetation), although the water requirement and drought tolerance of vegetation in this ecological region are worth studying further. Another important reason for the difference is the interference of human activity, which leads to relatively weak correlation between NDVImax and annual precipitation in the typical desert vegetation area (Dai et al., 2010).

Only $7.64 \%$ of the desert vegetation showed significant positive correlation between NDVImax and annual precipitation in the Shule River Basin (an extremely arid area in northwestern Hexi region), which was obviously lower than those in the Shiyang River Basin (35.74\%) and Heihe River Basin (38.83\%). These results showed that precipitation has little influence on desert vegetation growth in the Shule River Basin. This phenomenon was also found in other extremely arid regions of Northwest China (Chen et al., 2001). The reasons may be as follows. The Shule River Basin is an extremely arid area and the annual precipitation in this basin was only about 50 $\mathrm{mm}$ in the past three decades, which was lower than those in the Shiyang River Basin (220 mm) and Heihe River Basin $(120 \mathrm{~mm})$. Due to long-term stress of extreme drought and sparse precipitation, desert vegetation developed strong adaptability to drought conditions (Jiang, 2003). Moreover, desert vegetation growth is not only depending on natural precipitation but maybe on groundwater, deeper soil water and runoff volume (Jiapaer et al., 2007; Li et al., 2009). Previous studies also suggested that significant correlation between NDVImax and annual precipitation was found in an arid area of Northwest China, where the annual precipitation is greater than 180 mm (Li and Chen, 2014).

\section{Conclusions}

The study concluded that the desert vegetation was generally improved in Hexi region over the past 
three decades. The average value of NDVImax during the growing season showed an increasing trend at the rate of $0.65 \times 10^{-3} / \mathrm{a}(P<0.05)$ from 1982 to 2013 , which included a fluctuating increasing phase (1982-2000) and a significantly increasing phase (2001-2013). About $40.51 \%$ of desert vegetation in Hexi region exhibited an obvious increasing tendency during 1982-2013, while 5.96\% of the total desert vegetation area exhibited a decreasing trend. In addition, the significant increases of desert vegetation mainly appeared in northwestern part of Hexi region.

This study determined that $95.32 \%$ of desert vegetation in Hexi region showed positive correlation between NDVImax and annual precipitation (with $49.27 \%$ and $46.05 \%$ showing significant and non-significant positive correlations, respectively), indicating that precipitation is a key factor for desert vegetation growth in the entire region. Moreover, the areas with non-significant positive correlation between NDVImax and annual precipitation mainly located in the lower reaches of Shiyang and Shule river basins. The WMC of desert vegetation mainly shifted to the lower reaches of the above two basins in the past 10 years, especially in the Shiyang River Basin, demonstrating that desert vegetation was improved in these regions, which may be mainly caused by human activities.

Only $7.64 \%$ of the desert vegetation showed significant positive correlation between NDVImax and annual precipitation in the Shule River Basin, indicating that in the extremely arid areas, desert vegetation growth might be strongly related to groundwater, deeper soil water, runoff and water use patterns instead of natural precipitation. In addition, the correlation between annual precipitation and NVDImax of mountain desert vegetation was higher than that of typical desert vegetation. However, few researches have focused on this phenomenon, and its mechanisms are needed to be further studied.

\section{Acknowledgments}

The study was supported by the Opening Foundation of the State Key Laboratory Breeding Base of Desertification and Aeolian Sand Disaster Combating, Gansu Desert Control Research Institute (GSDC201503), the National Natural Science Foundation of China $(41271024,31260129,31360204)$ and the Program for Innovative Research Group of Gansu Province, China (1506RJIA155). We also thank the members from the Institute of Glaciology and Ecogeography, College of Earth and Environmental Sciences, Lanzhou University for providing ArcGIS technical support in the data processing.

\section{References}

Chen Y H, Li X B, Shi P J. 2001. Variation in NDVI driven by climate factors across China, 1983-1992. Acta Phytoecologica Sinica, 25(6): 716-720. (in Chinese)

Dai S P, Zhang B, Wang H J. 2010. Spatio-temporal change of vegetation index NDVI in Northwest China and its influencing factors. Journal of Geo-Information Science, 12(3): 315-321. (in Chinese)

Deng C P. 2006. Research on vegetation changing and reaction to climate in Northwest China in the past 22 years. MSc Thesis. Lanzhou: Lanzhou University. (in Chinese)

Gerten D, Schaphoff S, Haberlandt U, et al. 2004. Terrestrial vegetation and water balance-hydrological evaluation of a dynamic global vegetation model. Journal of Hydrology, 286(1-4): 249-270.

Guo N, Zhu Y J, Wang J M, et al. 2008. The relationship between NDVI and climate elements for 22 years in different vegetation areas of Northwest China. Journal of Plant Ecology, 32(2): 319-327. (in Chinese)

Guo W, Ni X N, Jing D Y, et al. 2014. Spatial-temporal patterns of vegetation dynamics and their relationships to climate variations in Qinghai Lake Basin using MODIS time-series data. Journal of Geographical Sciences, 24(6): 1009-1021.

Han K S, Park Y Y, Yeom J M. 2015. Detection of change in vegetation in the surrounding desert areas of Northwest China and Mongolia with multi-temporal satellite images. Asia-Pacific Journal of Atmospheric Sciences, 51(2): 173-181.

Jamali S, Seaquist J, Eklundh L, et al. 2014. Automated mapping of vegetation trends with polynomials using NDVI imagery over the Sahel. Remote Sensing Environment, 141: 79-89.

Jeong S J, Ho C H, Brown M E, et al. 2011. Browning in desert boundaries in Asia recent decades. Journal of Geophysical Research, 116(D2), doi: 10.1029/2010JD014633.

Jiang X. 2003. Relationship between climate and geographic distribution of some plant species and prediction of species potential distribution in the arid land, Northwest China. MSc Thesis. Beijing: Institute of Botany, Chinese Academy of Sciences. (in Chinese) 
Jiapaer G, Chen X, Ma Z G, et al. 2007. Classification of sparse desert riparian forest in extreme arid region. Journal of Desert Research, 29(6): 1153-1161. (in Chinese)

Lei H M, Yang D W, Huang M Y. 2014. Impacts of climate change and vegetation dynamics on runoff in the mountainous region of the Haihe River basin in the past five decades. Journal of Hydrology, 511: 786-799.

Li Q H, Chen Y N. 2014. Response of spatial and temporal distribution of NDVI to hydrothermal condition variation in arid regions of Northwest China during 1981-2006. Journal of Glaciology and Geocryology, 36(2): 327-334. (in Chinese)

Li X B, Shi P J. 2000. Sensitivity analysis of variation in NDVI, temperature and precipitation in typical vegetation types across China. Acta Phytoecologica Sinica, 24(3): 379-382. (in Chinese)

Li X H, Shi Q D, Guo J, et al. 2009. The response of NDVI to climate variability in Northwest Arid Area of China from 1981 to 2001. Journal of Arid Land Resources and Environment, 23(2): 12-16. (in Chinese)

Li X R, Tan H J, He M Z, et al. 2009. Patterns of shrub species richness and abundance in relation to environmental factors on the Alxa Plateau: Prerequisites for conserving shrub diversity in extreme arid desert regions. Science in China Series D: Earth Sciences, 52(5): 669-680.

Li Z, Yan F L, Fang X T. 2005. The variability of NDVI over Northwest China and its relation to temperature and precipitation. Journal of Remote Sensing, (3): 308-313. (in Chinese)

Liu X F, Ren Z Y. 2012. Vegetation coverage change and its relationship with climate factors in Northwest China. Scientia Agricultura Sinica, 45(10): 1954-1963. (in Chinese)

Liu X L. 2001. Landscape pattern and systems coupling of the meta-ecosystem consisted of mountain, desert and oasis in Hexi Corridor, Gansu, China. PhD Dissertation. Lanzhou: Gansu Agricultural University. (in Chinese)

Mao D H, Luo L, Wang Z M, et al. 2015. Variations in net primary productivity and its relationships with warming climate in the permafrost zone of the Tibetan Plateau. Journal of Geographical Sciences, 25(8): 967-977.

Meng X J, Zhang S F, Zhang Y Y, et al. 2013. Temporal and spatial changes of temperature and precipitation in Hexi Corridor during 1955-2011. Journal of Geographical Sciences, 23(4): 653-667.

Mu S J, Li J L, Chen Y Z, et al. 2012. Spatial differences of variations of vegetation coverage in Inner Mongolia during 2001-2010. Acta Geographica Sinica, 67(9): 1255-1268. (in Chinese)

Murray S J, Watson I M, Prentice I C. 2013. The use of dynamic global vegetation models for simulating hydrology and the potential integration of satellite observations. Progress in Physical Geography, 37(1): 63-97.

Piao S L, Friedlingstein P, Ciais P, et al. 2006. Effect of climate and $\mathrm{CO}_{2}$ changes on the greening of the Northern Hemisphere over the past two decades. Geophysical Research Letters, 33(23), doi: 10.1029/2006GL028205.

Song K S, Zhang B, Duan H T, et al. 2005. Dynamic changes of forest in mid-east Jilin Province in the past 20 years. Resources Science, 27(2): 77-82. (in Chinese)

Wang H J, Jin X H, Li H L, et al. 2010. NDVI variation and coupling analysis with climate change in Northwest of China based on GIS and RS. Transactions of the CSAE, 26(11): 194-203. (in Chinese)

Wang H L, Chen A F, Wang Q F, et al. 2015. Drought dynamics and impacts on vegetation in China from 1982 to 2011. Ecological Engineering, 75: 303-307.

Wang J Y, Chang X X, Ge S L, et al. 2001. Vertical distribution of the vegetation and water and heat conditions of Qilian Mountain (Northern Slope). Journal of Northwest Forestry University, 16(Suppl.): 1-3. (in Chinese)

Wei Z F, Wang D G, Zhang C, et al. 2014. Response of vegetation cover to climate change and human activities in Northwest China during 1999-2010. Journal of Desert Research, 34(6): 1665-1670. (in Chinese)

Xin Z B, Xu J X, Zheng W. 2007. Spatiotemporal variations of vegetation cover on the Chinese Loess Plateau (1981-2006): Impacts of climate changes and human activities. Science in China Series D: Earth Sciences, 51(1): 67-78.

Yang X M, Yang T B, Ji Q, et al. 2014. Regional-scale grassland classification using moderate-resolution imaging spectrometer datasets based on multistep unsupervised classification and indices suitability analysis. Journal of Applied Remote Sensing, 8(1): 083548, doi: 10.1117/1.JRS.8.083548.

Zhang B Q, Wu P T, Zhao X N. 2011. Detecting and analysis of spatial and temporal variation of vegetation cover in the Loess Plateau during 1982-2009. Transactions of the CSAE, 27(4): 287-293. (in Chinese)

Zhang G L, Xu X L, Zhou C P, et al. 2011. Responses of vegetation changes to climatic variations in Hulun Buir grassland in past 30 years. Acta Geographica Sinica, 66(1): 47-58. (in Chinese)

Zhang T Y, Wang H S. 2015. Trend patterns of vegetative coverage and their underlying causes in the deserts of Northwest China over 1982-2008. PLoS ONE, 10(5): e0126044, doi: 10.1371/journal.pone.0126044.

Zhao M S, Fu C B, Yan X D, et al. 2001. Study on the relationship between different ecosystems and climate in China using NOAA/AVHRR data. Acta Geographica Sinica, 56(3): 287-296. (in Chinese)

Zhao X, Tan K, Zhao S, et al. 2011. Changing climate affects vegetation growth in the arid region of the northwestern China. Journal of Arid Environments, 75(10): 946-952.

Zhou W, Gang C C, Li J L, et al. 2014. Spatial-temporal dynamics of grassland coverage and its response to climate change in China during 1982-2010. Acta Geographica Sinica, 69(1): 15-30. (in Chinese) 